\title{
A Case Study for Technical and Vocational Education and Training Professional Development Training in Untact Era: Focusing on Official Development Assistance Project in Botswana
}

\author{
Youngmin Lee ${ }^{1}$, Woocheol Kim², Heajung Woo ${ }^{3 *}$
}

${ }^{1}$ Division of Lifelong Vocational Education Research, Korea Research Institute for Vocational Education \& Training, Sejong National Policy Research Complex, 370, Cityhall-Daero, Sejong V city, 30147, REPUBLIC OF KOREA

${ }^{2}$ Department of Human Resource Development,

Korea University of Technology and Education, 1600, Chungjeol-ro, Byeongcheon-myeon, Dongnam-gu, Cheonan-si, Chungcheongnam-do, 31253, REPUBLIC OF KOREA

${ }^{3}$ Human Resources Development Institute,

Korea University of Technology and Education, 18, Gwasuwon-gil, Seobuk-gu, Cheonan-si, Chungcheongnam-do, 31079, REPUBLIC OF KOREA

*Corresponding Author

DOI: https://doi.org/10.30880/jtet.2021.13.02.002

Received 01 ${ }^{\text {st }}$ February 2021; Accepted 04 ${ }^{\text {th }}$ March 2021; Available online $30^{\text {th }}$ June 2021

\begin{abstract}
The prolonged COVID-19 pandemic has disrupted the TVET professional development training, which was planned to be carried out in a face-to-face manner. This study aims to examine TVET professional development training based on the ADDIE model and provide implications for ODA and TVET professional development training in the post-COVID era. In this case study, a TVET training program for Botswana was developed based on the ADDIE model in an untact environment. Accordingly, the performance activities for each phase of analysis, design, development, implementation, and evaluation were analyzed, and based on this, implications for ODA and TVET were provided. This study identified the applicability of non-face-to-face education in the ODA project. Also, this study explored how to develop systematic and dimensional programs based on the ADDIE model in a non-face-toface manner. In addition, sustainability could be secured through cooperative partnerships between donor and beneficiary countries from the perspective of SDGs Goal.
\end{abstract}

Keywords: TVET, professional development training, Bostwana, untact learning, ODA, Korea

\section{Introduction}

Since the World Health Organization (WHO) declared the rapidly spreading Coronavirus disease (COVID-19) outbreak a pandemic, this pandemic has changed the world rapidly (UNCTAD, 2020a). Due to the COVID-19 pandemic, the shift from a face-to-face economy to a non-face-to-face economy has spread, and the ways of working, living, and learning were drastically changed to be non-face-to-face (Lee, Kim, \& Park, 2020; Nam \& Lee, 2020). The effect of the pandemic on international exchanges is even more pronounced. Some countries have even restricted domestic movements by imposing nationwide lockdowns, and most countries have closed their borders to restrict entry 
and exit between countries (Kwon, 2020; UNCTAD, 2020b).

With the prolonged pandemic situation, this change has also affected official development assistance (ODA) projects that promote national-level development cooperation. The limited movement between countries has caused many difficulties in carrying out face-to-face international development cooperation projects. Although such ODA projects are based on multinational and multilateral cooperation, the prolonged pandemic has disrupted such cooperation, which has led to some of the 2020 budgets being diverted to other places or delayed schedules (Donor Tracker, 2020; PIDA, 2020; Van de Poel, 2020). In the meantime, COVID-19 has been unexpectedly advancing the era of digital transformation. The end of COVID-19 will not return to the pre-COVID-19 situation. New changes have also emerged in the education sector. There has been a growing interest in how non-face-to-face education replaces existing face-to-face education and effectively operates non-face-to-face education (Iivari, Sharma, \& Venta-Olkkonen, 2020; Soto-Acosta, 2020). The ODA education sector is also in a phase of transition to new ways by reflecting this change.

As of now, most ODA projects have been organized in terms of face-to-face-oriented activities. Occasionally, a few of the projects included non-face-to-face meetings. However, in the past, "face-to-face" projects accounted for a large portion of ODA projects and lacked preparation or understanding of non-face-to-face operations generally. Regarding the ODA projects in the education sector, activities are implemented with local training and invitation training, which mainly dispatched experts in a beneficiary country or trained selected trainees in experts' countries (KOICA, 2019). The main reason why face-to-face methods have been mainstream in the ODA project is that due to the nature of international development cooperation, multilateralism and multilateral communication should be preconditioned. The recipient countries' ICT infrastructure has not been smooth enough to apply online-based non-face-to-face environments (Song, 2020). However, in spite of the prolonged and uncertain COVID-19 situation, considering that the ODA project cannot be suspended or postponed until it is fully overcome, the need for a new way of doing business has emerged.

Technical and vocational education and training (TVET) is an important sector in the ODA project that can promote self-directed and sustainable development by strengthening human resources in developing countries (Kim, Shin, Woo, \& Kim, 2019). Due to the influence of the pandemic, the need to strengthen the quality of the TVET sector has been increasing to respond to the surge in unemployment and changes in demand in the labour market (Blustein, Duffy, Ferreira, Cohen-Scali, Cinamon, \& Allan, 2020; Jain, Budlender, Zizzamia, \& Bassier, 2020). In addition, it has become more pivotal to enhance self-directed development capabilities by strengthening the TVET sector in developing countries, especially under the current pandemic circumstance where domestic movements and those between countries, are controlled and restricted unpredictably (Van de Poel, 2020). In order to enhance TVET quality, the excellence of contents, appropriateness of educational environment, and professionalism of trainers are required. The professionalism of teachers, who directly interact with students and deliver educational content, is considered more vital for the sustainable development of countries (Woo, Kim, Yi, \& Yoon, 2018).

Previously, TVET programs were also carried out in a face-to-face manner (KOICA, 2019). Their entire process, including analysis, design, development, implementation, and evaluation, was done face-to-face. As such, the TVET program based on the ADDIE model was able to achieve the desired purpose and ensure its effectiveness (Lam, \& Hassan, 2018; Ismail, Zakaria, Ismail, Othman, \& Samsudin, 2019). However, in this process, face-to-face communication was mainly implemented with a complementary e-mail approach. With great constraints on adhering to the same communication methods as in the past, doubts about proper procedures based on ADDIE or ensuring quality assurance with effective and efficient communication methods have grown in the untact era (Kwon, 2020; Song, 2020).

Given the above, it is necessary to seek alternatives to overcome changes in the new environment of the untact era (Song, 2020). Existing face-to-face projects have performed well based on smooth communication, but due to limited budget, only a small number of people were able to benefit from education, and there were limitations that repetitive learning was difficult after the end of the training (Fardoun, Montero, \& Jaquero, 2009; Lee, 2013). TVET training in an untact environment can be a turning point where TVET training becomes more advanced to overcome obstacles while maintaining the advantages of existing training methods as much as possible. Nevertheless, due to a lack of preparation and unforeseen circumstances, not many of research dealing with this topic. Training in an untact environment has the advantage of being effective in reducing costs and enabling efficient training beyond time and space. Nevertheless, training within an untact environment need to overcome some challenges for ensuring its effectiveness, such as overcoming physical distances in international cooperation, multilateral physical distance problems, and time-consuming problems when working multilaterally (Fardoun, Montero, \& Jaquero, 2009; Lee, 2013).

Therefore, this study aims to introduce a case of non-face-to-face TVET training in ODA with a case of the TVET professional development training conducted in Botswana. Based on the results, this study provides implications for future ODA TVET projects and non-face-to-face education to overcome various and potential constraints in the pandemic situation.

\section{Literature Review}




\subsection{ODA Project in Botswana}

The organization for economic cooperation and development (OECD)'s development assistance committee (DAC) defined ODA as "government aid that promotes and specifically targets the economic development and welfare of developing countries (p.1)." The ODA performs international development cooperation activities aimed at economic growth, the spread of democracy, peace and stability, sustainable development, and the resolution of poverty.

The organization for economic cooperation and development (OECD)'s development assistance committee (DAC) defined ODA as "government aid that promotes and specifically targets the economic development and welfare of developing countries (p.1)." The ODA performs international development cooperation activities aimed at economic growth, the spread of democracy, peace and stability, sustainable development, and the resolution of poverty. In the past, the ODA paid attention to coping with absolute poverty, but since 2010, the focus has moved beyond poverty eradication and toward sustainable development. Specifically, the ODA primarily focuses on achieving Sustainable Development Goals (SDGs) between 2016 and 2030, while the SDGs include 17 goals and 169 detailed goals (OECD, 2020). In 2019, the ODA budget for OECD member countries reached 152.8 billion (OECD web, 2020).

The ODA project establishes the direction and scope of international development cooperation by considering problem analysis, demand analysis, and international comparative advantage of donor countries. The major areas of ODA support in Korea include education (including TVET), health, administration (information and communication technology, economy), agriculture, industrial energy (land development) and the environment (green growth) and women. In particular, the Korean government has recently focused on providing support for health, education, and agriculture development in developing countries (KOICA, 2019). The TVET sector is largely related to SDGs' fourth goal, quality education, and the eighth goal, decent work economic growth. The TVET sector aims to enhance the competitiveness of human resources through quality education and promote sustainable economic growth in developing countries based on these human resources.

Most recently, the ministry of education and skills development in Botswana put an emphasis on skills development and TVET strategy with a considerable investment in TVET to be able to drive the economy and fill human resource gaps. Key issues in TVET in Botswana are relevance, quality, and access. Despite a huge investment in infrastructure and policy reforms for TVET, access has insufficiently increased and skills gaps and mismatches are still considered major issues. Monitoring and evaluating overall performance of the TVET system, in particular with regard to impact, has not been developed (Kim et al., 2019; Woo et al., 218). There is a paucity of data, resulting from no integrated data collection or management information system for TVET, which would lead to poor information for management decisions. In this regard, the Korean government supported the quality improvement of TVET in Botswana through the V-CODE (Vocational education-COmpetence DEvelopment) project. The Korean Ministry of Education conducted TVET projects in five countries (Botswana, DR Congo, Malawi, Namibia, Zambia) in the Southern African development community (SADC) region for five years from 2011 under the name of the Better Education for Africa's Rise (BEAR) project.

Based on the performance of the BEAR project, the need for follow-up projects related to TVET emerged for the beneficiary countries for sustainable development. In response, the Korean government conducted the V-CODE project to develop educational capacity at the school sites in 2016-2020 based on the BEAR project. The ultimate goal of the project was to enhance the capabilities of human resources in the TVET field in Botswana (Jeon et al., 2019).

\subsection{ADDIE}

\subsubsection{ADDIE as ISD Model}

The systematic approach teaching design model consists of several components which are closely related to each other (Gustafson \& Branch, 2002). The ISD model is viewed as a systematic activity in which all components develop an education program together collectively to achieve the goals set out. Thus, the process is repeated until the intended objective is achieved, and all components interact with each other, so if a change occurs in a particular element, the change should be reflected in other elements. This enables the effective and attractive development of education programs with optimal cost and effort (Branch, 2009; Oh \& Choi, 2014).

ADDIE is the most representative ISD model, named after the first letters of each phase that constitutes the model: analysis, design, development, implementation, and evaluation. More than 100 ISD models have been proposed, but most are based on a typical ADDIE model (Fardoun, Montero, \& Jaquero, 2009). Analysis is to identify learners' characteristics, expectations, and needs, including environmental conditions, in order to set up intended goals. Design is the design of all aspects of training based on the results of the analysis process. This phase includes clarifying training goals in behavioral terms, selecting the assessment tool to meet the training goals, and establishing training strategies to align and train learners. Development is actually to develop and produce teaching materials to be used in classes according to design specifications. The development phase includes the development of teaching materials, prototype development, and evaluating tools. Implementation includes continuous maintenance and management of changes using training programs designed and developed in real-world sites. Evaluation is to assess all the outcomes of the execution process 
including performance, satisfaction, appropriateness, efficiency and improvements (Allen, 2006; Branch, 2009; Oh \& Choi, 2014; Reigeluth, 2013).

\subsubsection{Applied ADDIE in an Untact Environment}

'Untact' is a combination of 'contact' and 'un-' which means negation, and refers to new consumption trends, such as purchasing goods without contacting clerks through the development of technology (Kim et al., 2018). Due to the prolonged paradigm of COVID-19, the impact of these untact trends has also affected the education sector. Previously, education including regular education and TVET were mostly conducted in a face-to-face manner. Some lifelong education and job training were conducted in the form of face-to-face and online education, while some educational contents were produced in an online environment. Education in the untact environment has become the paradigm to replace face-to-face education by online learning or e-learning, which used to be only a part of education (Lee, Kim, \& Park, 2020; Nam \& Lee, 2020). Prior to the COVID-19 pandemic, education in a non-face-to-face environment such as distance education, online learning, e-learning, and smart learning was commonly implemented. In order to become more effective at training in an unprecedented transition to untact education, it is necessary to refer to ISD models and components such as online learning, e-learning, and smart learning.

Distance education has a history of about 170 years, starting with education using mail communication between students and teachers (Taylor, 2001). "Distance education is characterized by teaching and learning being brought about by media: in principle students and their teachers do not meet face-to-face.” (Holmberg, Bernath, \& Busch, 2005, p.9) Online learning or e-learning is also used to deliver various content, including university, primary and secondary education, as an educational strategy or a role of education itself. Recently, online-based education such as flipped learning and blended learning with e-learning is also easily accessible. Meanwhile, smart learning is distinguished from traditional e-learning in that it utilizes the advantages of smart devices such as smartphones and tablet PC (personal computer) as a learning method (Lee, 2013).

The ADDIE model has also been applied in education in the above untact environment. According to a prior study, ADDIE can be flexibly applied even in an untact environment, and various components need to be considered in the development phase to facilitate smooth interaction. For example, platforms (e.g., LMS), contents, devices and display devices, the cloud, communication environment, and communities of practice $(\mathrm{CoP})$ should be considered (Fardoun, Montero, \& Jaquero, 2009; Lee, 2013).

\section{Method}

\subsection{Method and Procedure}

This study aims to examine Botswana TVET professional development training cases and draw implications based on the ADDIE model. To achieve the purpose, this study proceeds in accordance with each phase of the ADDIE model. First of all, the analysis phase included a needs analysis, learner analysis, and problem analysis based on a literature review, e-mail, and communication over the phone. Second, the design phase included design of the content and environment for the training program based on analysis results. Third, the development phase included development of specific materials for use in implementing education programs. The fourth implementation phase included a rehearsal and three sessions. In the final step, the evaluation phase allowed for confirmation of the performance of the training program and derived modifications for improvement. The evaluation was conducted based on data collected through interviews and reviews of stakeholders including participants who participated in the training.

This study intended to contribute to the sustainable and self-directed development of the beneficiary countries by actively reflecting the opinions of experts in donor country (Korea) that provided educational programs as well as the recipient country (Botswana). Therefore, the entire phase of ADDIE was led by the project manager and the SME of Korea based on continuous and close consultation between the two countries. In particular, design and development phases first developed rough design drafts designed by Korea and sent them to Botswana, and Botswana (the policy coordinator, research institute, and university) gave feedback on Modipi's opinions and designed detailed contents based on opinions in the feedback. In addition, an IT expert (ITE) in Korea continued to participate in the event, considering the educational untact environment.

\subsection{Case Study Object}

This study is a case study on TVET training conducted in the context of the COVID-19 pandemic. Case studies can derive empirical knowledge by intensively studying specific cases made in specific situations (Yin, 2009). This case study is based on the untact TVET professional development training conducted in 2020 as part of the ODA project between Korea and Botswana called the V-CODE project. TVET professional development training was organized as the last activity of the Botswana V-CODE project since 2016. Since the beginning of the MOU partnership in 2017, the agreed methodology and approach was for the realization of activities through face-to-face capacity-building in Botswana, invitational visits in South Korea, and sharing expertise on the South Korea TVET system and experiences of the Botswana TVET college system. The year 2020 was the last year of the five-year V-CODE project. To achieve the 
continuous capacity enhancement of the beneficiary country's TVET as the project's core goal, it was necessary to achieve a successful conclusion through continuous implementation of the TVET professional development training without discontinuing the project.

As the prolonged pandemic cut off cross-border movement and uncertainty was high, even some ODA projects have been discontinued. TVET professional development training, which is the object of this study, has also become difficult because of the need to send experts to Botswana or conduct training in Korea as scheduled. However, if the project were to be discontinued or postponed, it would be unlikely to achieve its original purpose or the expected and desired results. At the same time, uncertainty over the pandemic situation made it more urgent to settle cultural and training programs that can continue to develop Botswana TVET capabilities on a self-directed basis, even if the pandemic continues in the future. As a result, the training urgently needed to continue as scheduled by identifying appropriate methods in the untact environment. Nevertheless, problems such as lack of related experience and infrastructure still remained as challenges to be solved in the new untact era.

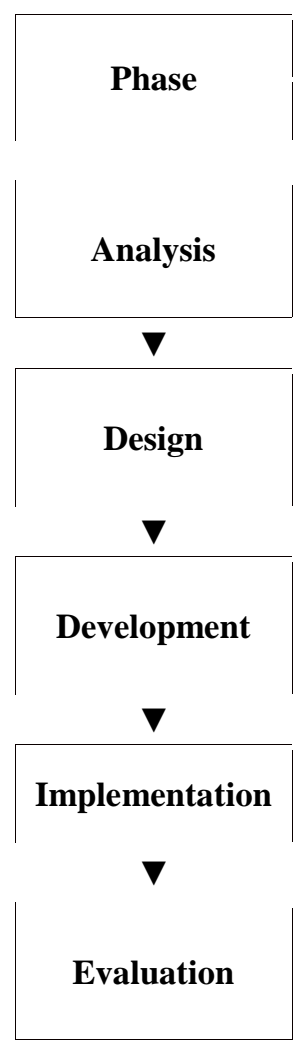

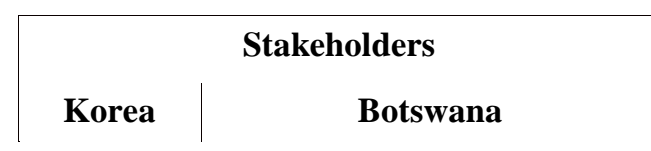

PM, SME, ITE

Policy-maker, research institutions, and technical colleges

\begin{tabular}{|c|c|}
\hline PM, & $\begin{array}{c}\text { Policy-maker, research } \\
\text { institutions, and technical } \\
\text { colleges }\end{array}$ \\
\hline
\end{tabular}

- Development of a cloud-based platform

- Development of contents and activities

- Development of management

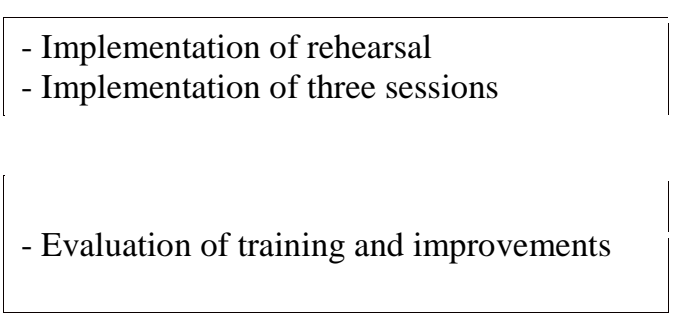

\begin{tabular}{|c|c|}
\hline PM, & $\begin{array}{c}\text { Policy-maker, research } \\
\text { SME, ITE }\end{array}$ \\
$\begin{array}{c}\text { institutions, and technical } \\
\text { colleges }\end{array}$ \\
\hline
\end{tabular}

\begin{tabular}{|c|c|}
\hline PM, ITE & $\begin{array}{c}\text { Research institutions and } \\
\text { technical colleges }\end{array}$ \\
\hline
\end{tabular}

PM, SME, ITE
Policy-maker, research institutions, and technical colleges

Fig. 1 - Research procedures

\section{Results}

\subsection{Analysis Phase}

\subsubsection{Task Analysis}

Based on the literature review and communication among the two parties, the results of task analysis for setting the direction of training are as follows. First, there is a need to enhance the evaluation capability of the TVET field, which is lagging behind at the national- level. According to Botswana reports, the evaluation of the current Botswana TVET area mainly implements the achievement of intended goals (theoretical and practical), the level of skill acquisition, program certification, and educational environment evaluation. More than $70 \%$ of the programs currently in operation have both theoretical and actual evaluation components. The current TVET evaluation area strives to maintain the quality conditions required for each program. Nevertheless, to improve the overall quality of education, there is a need to enhance the ability to evaluate areas that lag behind and require improvement. Based on these circumstances, Botswana requested support to enhance TVET evaluation capabilities for quality control of TVET.

Second, the lack of item banks (i.e., in and out scenario) has resulted in high predictability for examination, which has been shown to impede quality at the Quality Assurance and Assessment (QAA) unit. In particular, due to the inappropriateness of external modulators and the repeated use of these external modulators, there is also a lack of security. 
To compensate for these problems, the QAA workforce should be strengthened and the national evaluation bank should be activated.

Third, there is a lack of competencies to generate the examination items at the technical college level. The quality of the items is not guaranteed, and their quality assurance workforce is not sufficient. As a result, security or administration for the items is insufficient and targets are not met. Under these circumstances, there was a need for technical colleges to develop lecturers' evaluation capabilities and to expand assessment resources by developing an inter-institutional assessment bank.

\subsubsection{Analysis of the Characteristics of Training Targets}

The characteristics of the training target based on the status report of the question development of colleges are as follows: First, training targets lack expertise at evaluation. Botswana reports that despite the need for alignment between performance criteria and required evidence, the distribution of scores by question is not appropriate, computational errors appear in scoring tables and tests, there is lack of knowledge concerning question development, and lack of validation and reliability of questionnaires. This can be explained as difficulties arising from the lack of expertise in each content area.

Second, training targets lack practice opportunities. In actual evaluation situations, there was no test of the actual unit or the evaluation criteria were not concise, indicating that there was no room for capacity-checking in each performance area, and there was a lack of time, including for systematic practice.

Third, education conditions are inadequate. The number of registered students per class has sometimes made it difficult for each student to pay attention when evaluating all components of learning unit specifications (LUS) and at the school or institution level it has been shown that "the scoring criteria have increased too much, which may affect the consistency of the scores." In addition, there were some cases where they thought that there was a lack of support for reeducation in the development of questions. These difficulties can be attributed to inadequate conditions, such as lack of sufficient time and opportunities for capacity development for evaluators.

\subsubsection{Problem Analysis}

The following problems had to be considered in order to proceed with the TVET professional development training. First, the originally scheduled face-to-face training became impossible. The initial plan was a face-to-face in-country workshop with the Korean team travelling to Botswana in May 2020. Most planned activities were based on a face-toface approach. The advent of the COVID-19 pandemic resulted in travel restrictions and movement protocols for most countries, so that other solutions were needed to facilitate training considering the untact environment.

Second, disconnection problems arose between different stakeholders. Multiple blockages with cross-country and cross-regional movement made it difficult to move even within the same country. In a situation where face-to-face communication is impossible, phone calls and e-mails can be used for multilateral communication, but in such cases, 1:N communication can take place, which limits smooth communication multilaterally. As a result, problems arose in communication methods to facilitate multilateral stakeholders beyond time and space.

Third, a problem arose concerning cross-country gaps in digital skills. Due to the nature of the ODA project, smooth communication between countries should be the basic premise. However, in situations where face-to-face communication became difficult, it was necessary to adjust the digital gap to adapt to the mutual contact environment and align the communication framework to the inter-country untact environment.

Fourth, the question of how to share content and collaborate with trainees in the course of implementing training was derived. If content is shared by the existing method such as e-mail, it is difficult for instructors to check each trainee's content, and synchronous collaboration between trainees was also impossible. These communication methods are unsuitable for presentations, file sharing, storage and utilization. Therefore, new alternatives should be considered to address these problems.

Lastly, it was almost impossible to predict the end of the pandemic. The uncertain time of the end has made it uncertain when the face-to-face project will resume, and only indirect help could be provided by other countries rather than directly helping the recipient country. As a result, the need for self-directed and sustainable development of the beneficiary countries has become pivotal.

\subsection{Design Phase}

The design phase consists of education content design and educational environment design.

First, we conducted the content design of the training program based on the results of needs analysis and characteristics analysis. Need analysis results show that there is a need for assessment expertise, especially those related to question development. Characteristics analysis shows a lack of competence in question development, and a lack of practice opportunities or conditions for developing competencies. Based on these results, we derived the purpose and key objectives as follows: The purpose of the training program is to capacitate Botswana staff on the establishment of an item bank, and to enhance reliability, fairness, validity, accuracy and precision of assessment instruments. 
The key objective of the training program was to develop knowledge on measurement evaluation questions for TVET quality assurance with a view to: 1) Establish a basis for the item bank; 2) Develop question development methods and evaluation expertise; 3) Objectively assess learners' competencies through the development of valid and reliable evaluation questions. To achieve the educational purpose and objectives, thirty participants were recruited, which included a deputy director, a chief technical education officer, principal technical officers of program, development and delivery staff, policy divisions, and quality assurance and assessment and a technical college from Botswana.

Second, we conducted the educational environment design. As derived from the results of problem analysis, it was necessary to consider smooth many-to-many communication, file sharing, and utilization when designing the educational environment. The following educational environment design proceeded in order to facilitate education in online-based untact situations. The first point concerns use of a cloud-based platform. The cloud-based platform has been designed to implement smooth many-to-many interactions, content sharing, and collaborative activities among training participants online. The second point is designing a synchronous online workshop to achieve educational goals by transferring the contents through real-time workshops. For smooth progress, technical protocols for synchronous workshops were discussed in advance, and rehearsal is designed in the implementation phase to minimize the difficulties encountered during the workshop.

The third point concerns asynchronous practice sessions for performing self-directed learning tasks: this reflects the opinion that trainees have insufficient opportunities and conditions to practice, so that it is designed to accumulate enough practice opportunities and items developed through practice to encourage use in the future. This session utilizes the aforementioned cloud-based platform to enable smooth and synchronous collaboration between participants and feedback and interaction from professors during a practice session.

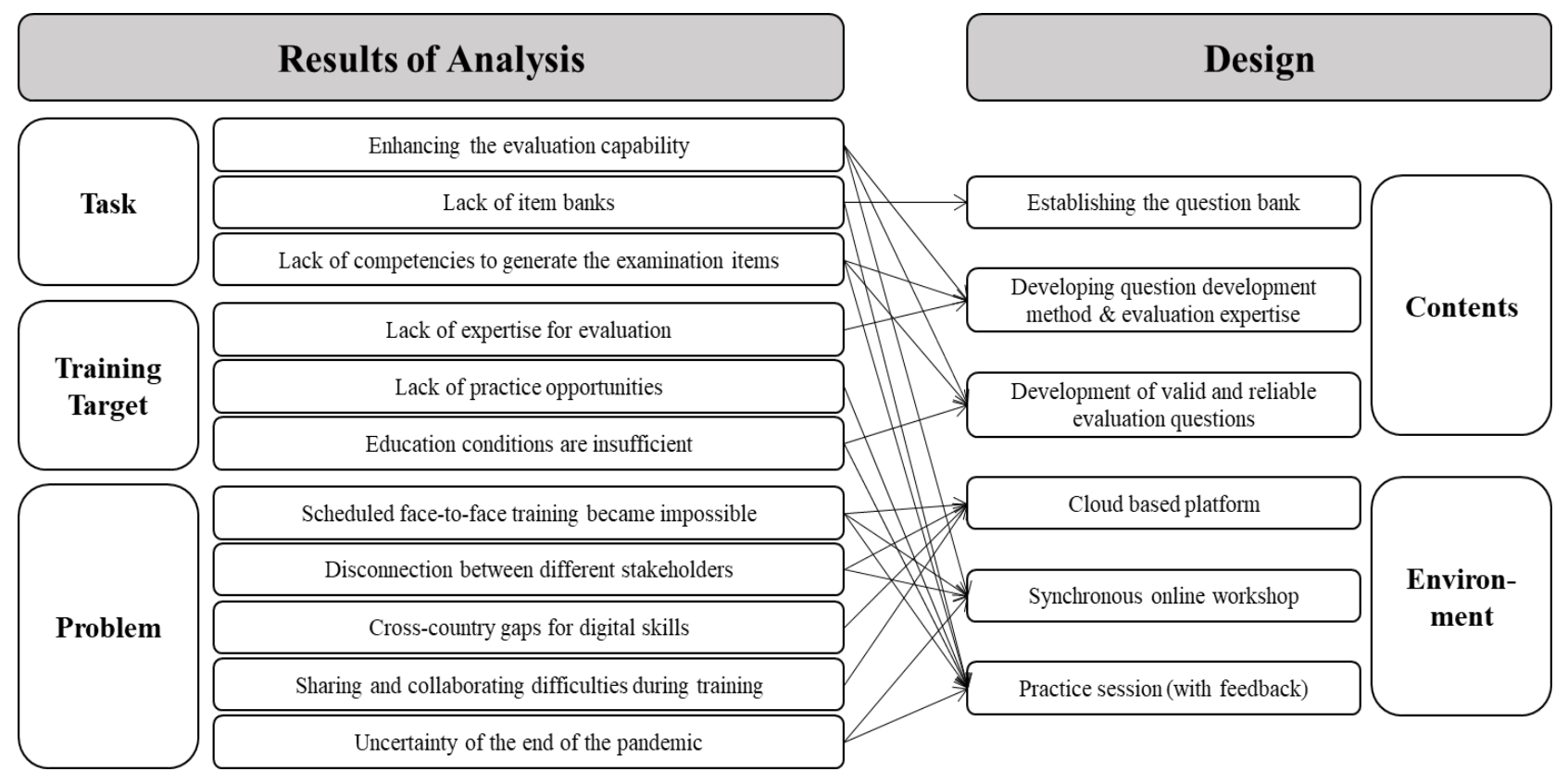

Fig. 2 - Design logic based on the analysis results

\subsection{Development Phase}

\subsubsection{Contents and Activities}

The main content of the online workshop covered the overall process and progress of item writing. The workshop mainly focused on the appreciation of item writing with acknowledgement of different levels of learning and understanding the concepts such as taxonomy. The main content also covered Bloom's taxonomy with the intention of helping the participants to assess and balance learning behaviours so that all learners are included in assessment. Furthermore, the content covered lessons on the need to explain the answers to learners who choose the wrong answers. In view of the above, TVET professional development training for quality assurance and assessment includes the following outline: 1) Bloom's Taxonomy Table, 2) Question Development, and 3) Answers \& Explanations.

To effectively transfer the content, the TVET professional development training was included in three sessions as follows: the first session is an introductory session to prepare Botswana participants for the second session (working period) by the Korean Team. The Korean team facilitated item writing and provided necessary guidance on the tasks that the teams had to embark on. The second session included a working period on the development of questions, explanations, and two-dimensional classification of test objectives. This session was the practical application component of the 
workshop where the college teams set out to develop items.

The third session included a report-back session by Botswana lecturers and feedback from Korean experts.

Table 1 - Schedule of TVET professional development training

\begin{tabular}{cl}
\hline Session (period) & \multicolumn{1}{c}{ Activities } \\
\hline & - An introduction of the TVET evaluation status for quality assurance in Botswana \\
& - The keynote speech (the current status and examples of TVET evaluation in Korea) \\
Session 1 & - An introduction of the TVET professional development program \\
& - A lecture on the development of evaluation items for TVET quality assurance \\
& - Explanation and delivery of the assignment \\
& - Explanation of instructions for using the cloud-based platform (video) \\
\hline \multirow{2}{*}{ Session 2 } & - Working on evaluation question development \\
& - Submission of work online by August 4 \\
\hline \multirow{3}{*}{ Session 3 3} & - Sharing of the work from session 2 \\
& - Content of developed questions, explanations, and two-dimensional classification of \\
& test objectives \\
& - Feedback \\
& - Sharing implications and future tasks \\
& - Wrap up and way forward
\end{tabular}

In order to proceed with these sessions, teaching materials were developed for developing evaluation questions for TVET quality assurance, and practical materials (forms and examples) and video which explains how to utilize the cloud platform.

Selective Type

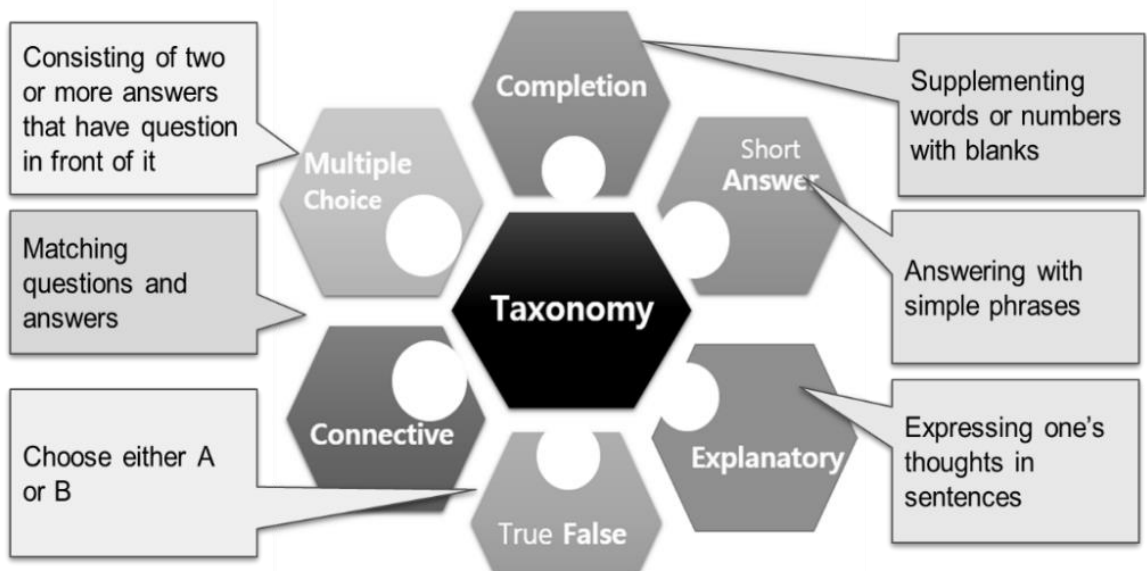

Fig. 3 - Example of teaching materials 


\section{Example of Taxonomy table}

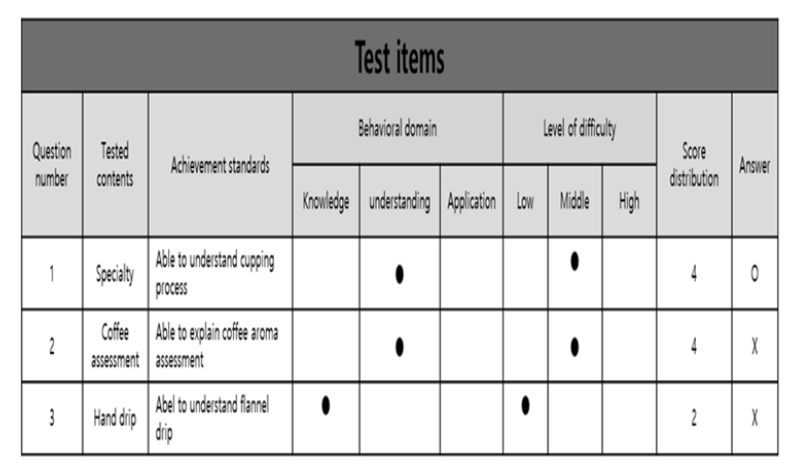

\section{Example of evaluation questions}

1.The process of clarifying the production history of coffee and checking the unique flavor is called cupping

Answer: TRUE

Explanation - Through the cupping process, the productio $\mathrm{n}$ history, unique aroma, as well as the difference between regular coffee and specialty coffee, can be distinguished.

Fig. 4 - Example of practical materials

\subsubsection{Cloud-Based Platform Development}

First, the TVET professional development training presupposes collaboration among countries, several Korean and Botswana stakeholders, and Botswana trainees as the target of this study. To meet this premise and facilitate training, this study utilizes a cloud-based platform from G Company. The cloud-based platform service has been developed to be available as an alternative to overcoming the challenges of non-face-to-face. The interface environment consists of mail, text (Chat), video conference (Meet), and cloud drives as following (figure 5), which enables smooth multilateral communication in an untact environment. Mail delivers 'accurate' information such as text, images, and shares link messages, drive information. Text (Chat) was used for simple and close communication for collaborating among trainees. Video conference (Meet) was utilized to share documents in a synchronous meeting such as a video conference, presentation, and to secure multilateral sympathy. By using a cloud-based platform, it became possible to smoothly communicate with various participants in real time, freeing from one-to-many, one-to-one communication. Besides, the cloud drive was used to store files, folders, and other tasks, and to collaborate and share specific tasks (such as assignments).

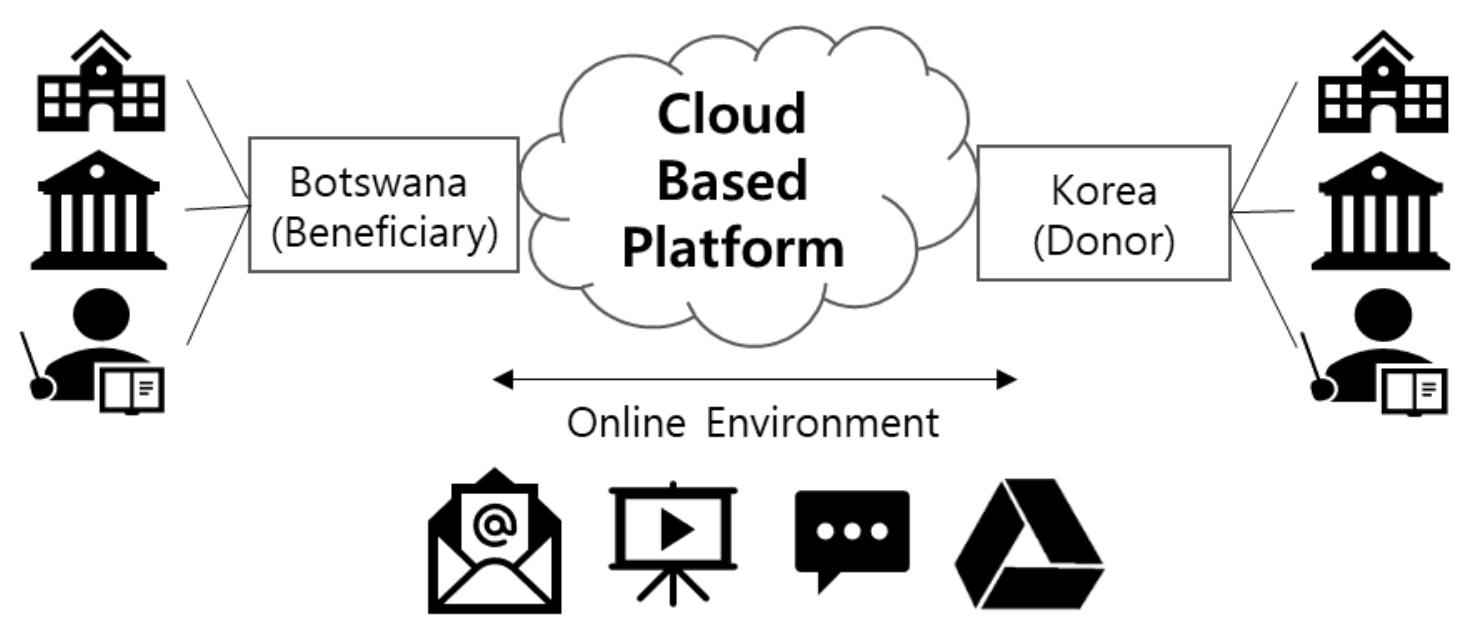

Fig. 5 - Cloud-based platform serviced by G company

\subsubsection{Management Development}

Conducting online workshops is definitely a new way of doing things for the Department of Teacher Training and Technical Education (DTT \& TE). Through the guidance and support of the Korean team, preparation for the online workshop did not seem daunting or intimidating. Management development, including support for communication, administration, and environment, was carried out to ensure the effectiveness of training in the untact environment.

First, smooth communication was necessary. The Korean team assisted the department to logon to the platform of $G$ company. This enabled the department easy access through the government data network. Day to day preparations were made through text and e-mail, which were also effective ways of sharing information among all participants. 
Second, administrative support was a challenge. Administratively, DTT \& TE and technical college management, members of the focal team and departmental IT unit offered support for the online workshop preparation. The department ensured that colleges received the necessary management and IT support. Officers at the department level were nominated to assist and support college teams when needed.

Third, environmental support was important. Due to limited IT resources within the department and technical colleges, the environment was not conducive for online interactions. The internet was slow, and in some instances, there were interruptions because the internet was down. However, to make the workshop a success, the department utilized IT resources from a local hotel. The use of a hotel meant that the department had to incur financial expenses for the use of faster and reliable internet. During the first workshop, colleges that were having difficulty connecting to the internet joined DTT \& TE officers at the hotel.

In addition, other support measures have been devised. A focal team consisting of DTT \& TE officers and representatives from all the colleges continued to play the pivotal role of preparing for Korea-Botswana workshops, and consequently provided support for the online workshops. The team discussed the draft programs and ensured that presenters were well-informed and ready to perform the tasks outlined in the workshop programs. Presenters were given deadlines for submission of their tasks to ensure smooth preparations.

\subsection{Implementation Phase}

\subsubsection{Rehearsals}

Rehearsals were implemented to ensure smooth running of the IT systems and the level of readiness of all presenters in the same environment as the actual training sessions. The Korean team continued to guide the focal team on what was expected to be done, including preparations for rehearsals. The focus of the rehearsal was to ensure that presentations and platform functions could be operated adaptively by presenters and various participants within the platform. With the participants from various fields, two nationalities and various regions, it took more than a month to ensure accurate communication using the platform mentioned above. The rehearsals proved to be very helpful because the department was able to gauge their readiness in terms of participating in the actual workshops. Gaps were identified, and advice was given on how to improve communication during the actual workshops. Multilateral communication protocols have been adjusted through verbal advice on how to log on and present and how to log on with all participants.

\subsubsection{First Session}

The first session was conducted as asynchronous online workshop via a video conference (Meet). At the beginning of the session, presenters from Botswana (quality assessment and assurance unit and college representatives) presented on the current status and challenges of evaluation of Botswana TVET results and the current status of question development respectively. After that, a Korean expert provided a lecture on how to develop evaluation questions to ensure TVET quality. Based on the following lectures, future tasks and manuals were introduced. Then the video showed how to use the cloud-based platform to perform the assignment. Figure 6 displays a scene of the lecture by a Korean expert.

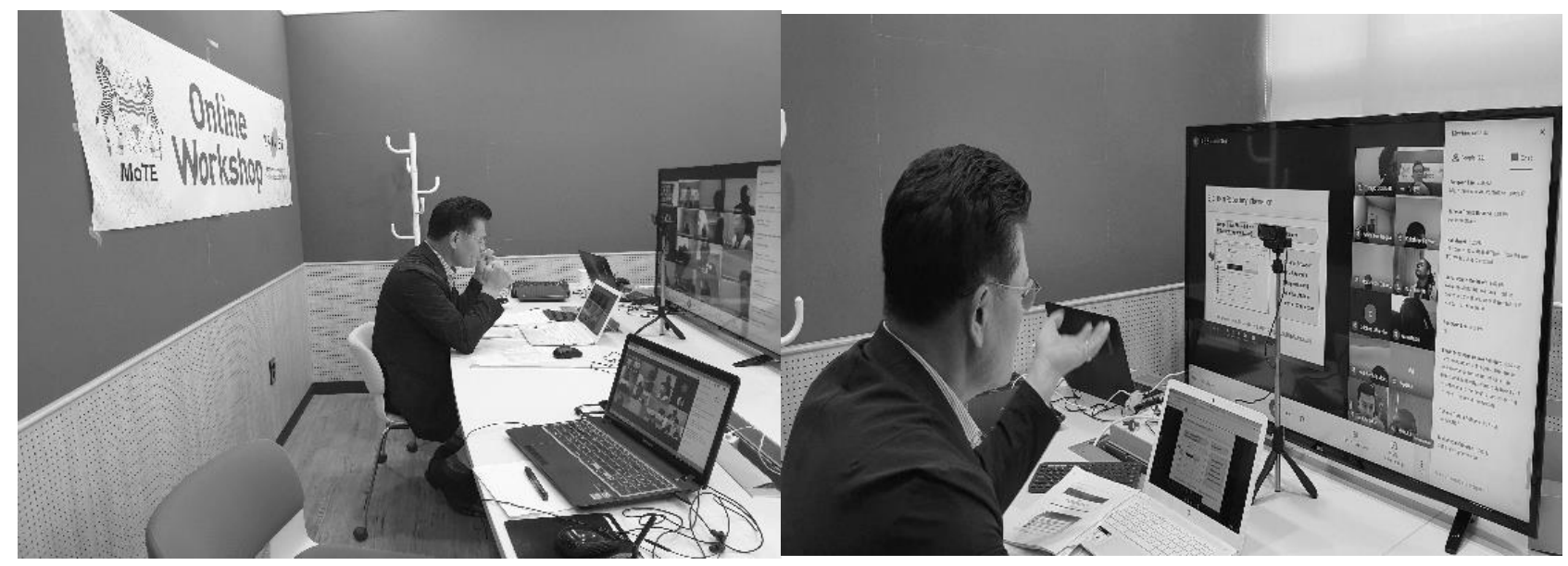

Fig. 6 - A Scene of synchronous untact training in the first session

\subsubsection{Second Session}

The second session of the asynchronous training program was allocated in a month's working period, and the task was assigned in the first session. During the process, Botswana participants performed a given task through collaboration 
using the cloud-based platform. By utilizing the cloud-based platform application for smooth collaboration with various participants from each country, participants were able to share, modify, edit, and update the files they worked on simultaneously. In addition, four members of each team shared and coordinated their opinions using Chat and Meet. At the same time, the Korean side monitored the performance process and the results of the participants, checking whether the work was going according to plan, and providing feedback on the results.

Development of materials entailed writing questions, explanations (including answers), and two-dimensional classification of test objectives. Each of four members in a team worked on a particular type of questions and consequently each team produced 6 types of questions, including 10 questions per each type (60 questions in total), their answers and explanations, and a taxonomy table for each program. Lecturers submitted their work online on the shared drives on August 5, 2020 in time for rehearsals.

\subsubsection{Third Session}

The third session was conducted as a synchronous training session on August 6, 2020. It consisted of presentations on sharing the training outcomes, feedback, implications and future tasks. First, Botswana participants shared their content of developed questions, explanations, and two-dimensional classification of test objectives. Next, the Korean expert shared the overall feedback on the second session, and finally, the Botswana representative presented the implications and future tasks, wrap up and forward. To maximize the training effect through reflective thinking, at the end of the third session, participants were assigned to the task of preparing a report, including the implications, performance, and future utilization achieved through three sessions.

\subsection{Evaluations Phase}

\subsubsection{International Development Cooperative Achievement}

The Botswana government effort on strengthening the TVET sector can help to develop economic potential. Furthermore, enhancing the quality of TVETs can be of great help to make meaningful contributions to the jobs needed. The Botswana government commented: "We experienced and learned that the strong link between the qualification framework and the TVET quality assurance greatly contributes to the improvement of TVET quality." It also contributed to ensuring and improving the quality of TVETs based on the continuous and active participation of TVET stakeholders.

International development cooperation (IDC) between Korea and Botswana not only secured the sustainability of existing projects but also contributed to developing economic potential through the TVET sector. The transfer of skills and expertise was not limited to the program areas (e.g., hospitality management, hairdressing) provided by the existing project, but has extended the scope to engineering and health and well-being programs. The online interaction and communication method applied in this training suggests that continuous cooperation between Korea and Botswana is ideal and possible beyond 2020. Botswana evaluated Korea's sharing of expertise as "very important and beneficial in promoting the growth of Botswana TVET."

Botswana complimented themselves on their achievement for "thinking of a new HOW of reaching our goal", "This is the first of its kind for us and we are proud that we are doing it.” This is worth noting that it is in line with SDGs goal 4 and 8 in that it aims to enhance the competitiveness of human resources through quality education and promote sustainable economic growth in developing countries based on these human resources.

\subsubsection{Educational Achievements}

The training held the workshops as planned. The significance of these workshops is that all college lecturers are learning new and improved ways of doing things at the same time. There would be harmony, cohesion and standardization in handling assessments. Cooperation with Korea has contributed immensely in providing a platform for sharing of new ideas and providing wider opportunities for learning through capacity-building and benchmarking activities. Through capacity-building activities, benefits were appreciated especially with the application rather than theoretical focus. This strong focus was noted during capacity-enhancement activities, namely portfolio development, teacher pack development and item writing.

There are three points of expected achievements from this training based on the feedback from Botswana as follows: The first point is an improvement in setting quality examinations that cover all levels of difficulties. In view of the fact that it was the first time TVET lecturers in Botswana used Bloom's taxonomy tables, they viewed the training as an eyeopener. Lecturers appreciated that the use of taxonomy tables allowed for a wide coverage of the unit or module. Unlike the current practice where only one form of questioning technique is used (short questions in the Botswana Technical Education program -BTEP), lecturers were exposed to different questioning techniques. Among other things, transition within levels of difficulty was achieved through the use of action verbs, and as a result shortcomings and errors were identified in the learning unit specifications for BTE programs. These shortcomings and errors imply that they will be looked into to ensure harmonization and corrections where necessary. To quote Botswana's feedback on this from the participants: "Other questioning techniques were developed and they were following the Blooms taxonomy. The items 
were developed according to LUS based on learning outcomes", and "This was a learning experience for all survey question developers."

The second point concerns upgrading the quality of the output (participants) in terms of facing the industry challenges with a well-rounded knowledge. Technical colleges appreciated that the cooperation would improve the quality of assessments development. The lecturers learnt that taxonomy tables brought clarity on assessments; as such, they are anticipating improvement in the pass rate. The cooperation has yielded desired spillover effects in that collaboration between technical colleges was improved. The implication is that lecturers will contribute to improving the quality of TVET by sharing knowledge and skills through cascading activities. Consequently, there will be a continued application of the lessons learned in colleges.

The third point concerns improved cohesion between assessors through the use of a standardized way of item writing, which is not discretionary but scientific-based. Developers had not dealt with the use of taxonomy tables prior to this exercise. The experience was well received and appreciated because it was an improvement to the way Batswana lecturers were dealing with issues of item writing. The wording in the taxonomy tables (use of active verbs) allowed the lecturers to detect shortcomings within the learning unit specifications (LUS) that are currently in use. This ensures that the department will not encounter the same problems. As a result, "The department facilitated the colleges by allowing them to use the newly reviewed learning programs that are being validated by Botswana Qualification Authority."

\subsubsection{Educational Infrastructural Achievements}

The move to use the untact platform yielded positive and constructive results. The untact mode closed the physical divide between Botswana and South Korea. Teams in Botswana from the four technical colleges and headquarters interacted and connected with the Korean team. The Korean team packaged all the items that the college teams produced.

However, difficulties occurred during the training process. Presenters from Botswana suffered from the use of technology, or the connectivity from the Botswana side was not stable (e.g., cutting of pictures, echo). Some audiences lacked discipline of using technology and forgot to turn off their microphones when they were not presenting. Some attended the workshop late, causing delays. Nevertheless, it helps to start investing in upgrading Botswana's ICT infrastructure. In addition, the training improves the technology environment by providing ICT equipment, and develops capacity and behaviour required thereof in the use of technology. A Botswanan gave the following evaluation in their reviews: "It minimized the risk by investing sufficient preparation in a timely manner." This was possible due to smooth communication based on the support of the management team of Korea and Botswana. In particular, Botswana evaluated that: "Task progress using the platform could be carried out effectively and efficiently." As a result, this was to allow technical college lecturers to work on the development and evaluation question. Evaluation question developers comprised teams from different disciplines such as Culinary Arts, Computer Networking, Electrical and Electronic Engineering, to mention a few.

According to a Botswana report, the following benefits were obtained through untact training: "reduced costs"; "networking opportunities"; "documentation through online storage"; "potential to train more people in a single session"; "increased facilitator - participant time"; "accessibility to expertise"; "information retention, new tools and social media encourage collaboration between participants and facilitators without barrier to space and time"; "Those same tools allow for the development of untact communities that can persist after the program/course is done"; "IT and the Internet can transform processes, institutions, the ways of teaching and learning and opening the door to innovation and new pedagogical theories."

Despite achieving infrastructure performance through the untact training, the following remain challenges to be addressed including "poor internet access/connectivity", "outdated ICT equipment", "inappropriate ICT basic technology", and “mindset”.

\subsection{Discussion and Conclusion}

Due to the COVID-19 pandemic, movement between countries and regions has become difficult. This prolonged situation has disrupted the TVET professional development training, which was planned to be carried out in a face-toface manner. This study is a case study of TVET professional development training that reflects new changes in the pandemic situation. This study aims to examine TVET professional development training based on the ADDIE model and provides implications for ODA and TVET professional development training in the COVID-19 era. Despite the new non-face-to-face environment, this study demonstrated a successful case of completing the untact training using a cloudbased platform, which contributed to improving the evaluation capabilities of training participants and the evaluation expertise of Botswana. Based on the results of this study, the following suggestions and discussions on ODA projects and TVET training are presented for the current and post-COVID-19 era.

First, this study identified the applicability of non-face-to-face education in ODA projects involving international and multiple parties. Most ODA projects tend to be carried out in a face-to-face format (KOICA, 2019). In order to continue the ODA project in the long-term situation of the unprecedented pandemic, it was inevitable to consider a new 
method. The biggest problem of education and training in the untact environment was the smooth communication between participants. TVET in ODA is even more so in terms of international projects (Kwon, 2020; Song, 2020). Therefore, it is important to establish environmental components that promotes smooth interaction (Lee, 2013). In that regard, this study examined and studied the online-based untact method to conduct TVET professional development training, and how to achieve the desired purpose with the positive evaluation. In the process of adopting an online-based approach in the untact era, the Korean side motivated for an alternative platform for the workshop, the online workshop. This supported a growth for the Botswana side despite the limitations in the stage of ICT infrastructural development in the technical colleges. These stakeholders made efforts to match the protocol between donor and beneficiary countries, such as providing a cloud-based platform.

This study revealed that non-face-to-face education could be applied to developing countries, including other African countries. Existing face-to-face training has comparative advantages at the communication level, but the continuous capacity development has been limited due to the considerable travel time of participating human resources and the potential for disconnection between learning times. In the existing face-to-face method such as field training and invitation training, only limited training participants could participate in training due to budget limitations, and due to the nature of face-to-face education, training has been implemented only during the training.

On the other hand, non-face-to-face education is relatively low in cost, allowing a large number of participants to participate in the training, and does not waste resources due to time and space. In addition, the effectiveness of education can be secured through synchronized communication between participants is possible by utilizing various platforms. Even if the COVID-19 pandemic ends, there may be no return to the situation before COVID-19. Given that, TVET professional development training in ODA would need to contemplate a paradigm shift from face-to-face to non-face-toface. This study might be an initial study to explore the possibility of untact training in ODA projects. This study could help in applying non-face-to-face methods to other related studies in the future. It was noted that there might be a need to allocate more time to a similar exercise in the future. If non-face-to-face training is carried out in future ODA projects, it is expected that additional measures to compensate for the shortcomings derived from this study will provide better quality education.

Second, systematic and dimensional programs can be developed based on the ADDIE model when designing nonface-to-face education programs, based on procedures of this study. Non-face-to-face education requires a different approach from traditional face-to-face education. This study proceeds with a case study that applies the ADDIE model in that an ISD model, that is widely used in both conventional face-to-face and non-face-to-face training. Although this study was based on the same process as traditional face-to-face training, there are differences in the specific components considered in each phase as non-face-to-face training is conducted. For example, it is necessary to check the differences in the learning environment in the analysis phase to coordinate protocols among participating countries through problem analysis for smooth untact training. In the design part, it is necessary to fully consider the design of the educational environment and the content design. In this training, unlike conventional non-face-to-face education methods, the cloudbased platform is applied by considering smooth communication, administrative, and environmental components. In the implementation stage, it also tried to solve communication and platform use problems through rehearsals for more than a month. This empirically supported that the ADDIE model can be flexibly applied to education in an untact environment (Fardoun et al., 2009; Lee, 2013). Based on this study, it is expected that the process under the ADDIE model in the untact environment can be carried out when designing non-face-to-face training programs in the future.

Third, sustainability can be secured based on cooperative partnerships between donor and beneficiary countries from the perspective of SDGs Goal. The Botswana TVET Professional Development Program, which is a target of this study, is a project involving several partners in both Botswana and Korea, and was conducted in a situation where an unexpected prolonged COVID-19 situation caused time and place limitations for the project to proceed. To ensure a successful project, this study emphasized close communication between donor and beneficiary countries throughout the ADDIE phase. Consequently, as presented in the evaluation phase, the improvement of evaluation expertise was achieved for the purpose originally established. In addition, Botswana assessed that its willingness and self-directedness to overcome the problem without avoiding it had been developed.

Because the ODA project aims to achieve a variety of SDGs, especially in the TVET sector, it is important to establish a self-directed foundation for the beneficiary country. International cooperation, in which donor countries simply support and beneficiary countries accept such support, does not help to establish a sustainable foundation for the recipient countries. From the perspective of SDGs, the effectiveness of the project can be seen as determined by the development of independent capabilities to develop self-directed capabilities of the beneficiary countries. This study argues that ODA projects, especially those related to TVETs, need to be carried out in this light.

The target of this study, TVET professional development training, involves the expertise of utilization of new platforms and vocational education and expertise in college programs (e.g. engineering, beauty, food). In the middle of the progress, various communication problems occurred as mentioned in the design and implementation phases. In order for TVET professional training to improve in a better direction in the future, this study suggests that the following challenges need to be overcome. First, it is essential to train professionals who are responsible for TVET professional training in an untact environment. In addition to TVET professional, training contents should include digital skills (digital literacy, understanding, uplift, and fluency). Second, it is vital to overcome the linguistic limitations of professional 
education experts in TVET areas. It is necessary to understand the official world language accurately and have sufficient fluency in their professionalterminology. Third, platforms that reflect environmental differences such as devices and ICT between countries need to be adequately provided. In future research, more advanced educational methods and various cases that can be used in an untact environment will be studied based on the research results and challenges presented in this study.

\section{Acknowledgement} project.

We acknowledge this study was conducted under the support of V-CODE (Vocational Competency Development)

\section{References}

Allen, W. C. (2006). Overview and evolution of the ADDIE training system. Advances in Developing Human Resources, $8(4), 430-441$

Blustein, D. L., Duffy, R., Ferreira, J. A., Cohen-Scali, V., Cinamon, R. G., \& Allan, B. A. (2020). Unemployment in the Time of COVID-19: A research agenda. Journal of Vocational Behavior, 119, 103436

Branch, R. M. (2009). Instructional design: The ADDIE approach. New York: Springer Science \& Business Media

Donor Tracker (2020). South Korea shifts ODA budget further toward COVID-19 response. Derived from https://donortracker.org/SouthKorea-shift-\%20ODA-budget-COVID-19-response (2021.01.14)

Fardoun, H., Montero, F., \& Jaquero, V. L. (2009). eLearnig XML: Towards a model-based approach for the development of E-learning systems considering quality. Advances in Engineering Software, 40(12), 1297-1305

Gustafson, K. L., \& Branch, R. M. (2002). What is instructional design. Trends and issues in instructional design and technology, 2, 10-16

Holmberg, B., Hrsg. Bernath, \& Busch, F. W. (2005). The evolution, principles and practices of distance education. Oldenburg: Bis

Iivari, N., Sharma, S., \& Ventä-Olkkonen, L. (2020). Digital transformation of everyday life-how COVID-19 pandemic transformed the basic education of the young generation and why information management research should care? International Journal of Information Management, 55, 102183

Ismail, M. I., Zakaria, A. F., Ismail, I. M., Othman, H., \& Samsudin, M. A. (2019). Design and development of augmented reality teaching kit: In TVET learning context. International Journal of Engineering \& Technology, 8(1), 129-34

Jain, R., Budlender, J., Zizzamia, R., Bassier, I. (2020). The labor market and poverty impacts of COVID-19 in South Africa. Cape Town: SALDRU, UCT. (SALDRU Working Paper No. 264)

Jeon, J., Kim, S., Kim, C., Lee, Y., Jeon, J., Kim, Y., \& Park, T. (2019). 2019 BEAR I sustainability reinforcement project (2019 V-CODE project). Sejong: KRIVET

Kim, R., Jeon, M., Lee, H., Choi, J., Lee, J., Kim, S., Lee, S., Seo, Y., \& Kwon, J. (2018). Trend Korea 2018. Seoul: Miraebook publishing

Kim, W., Shin, H. Y., Woo, H., \& Kim, J. (2019). Further training needs for TVET trainers: lessons from a national survey on Rwandan TVET trainers' instructional competencies. Journal of Technical Education and Training, 11(2), 32-45

KOICA (2019). A report of preliminary investigation for developing technical education programs at Al-Balqa Applied University in Al-Karak and Irbid. Seongnam: KOICA

Kwon, H. (2020). Policy options for international development cooperation in the COVID pandemic: A global perspective. International Development and Cooperation Review, 12(3), 23-29

Lam, K. W., \& Hassan, A. (2018). Instructional technology competencies perceived by technical and vocational education and training (TVET) students in Malaysia. International Journal of Academic Research in Business and Social Sciences, $8(5), 343-366$

Lee, D., Kim, S., \& Park, N. (2020). The block chain-based online learning platform for the untact education environment in the post-COVID-19 era. Journal of KIIT, 18(11), 109-121

Lee, J. (2013). Smart learning. Seoul: BookLab

Nam, C. U., \& Lee, Y. T. (2020). A study on the post-corona engineering education: A mid-term plan of engineering 
education for the revolution of post-Corona education. Ingenium, 27(2), 31-33

OECD (2020.apr). Official Development Assistance (ODA). Derived from https://www.oecd.org/dac/financingsustainable-development/development-finance-standards/official-development-assistance.htm

Oh, Y. \& Choi, J. (2014). Methodology of educational program development. Seoul: Hakjisa

PIDA (2020.7.20). Korea's international development cooperation in the post-Corona era, let's move to field force. Seoul: People's Instiative for Development Altermatives. derived from http://pida.or.kr/pium/?idx=4275020\&bmode=view

Reigeluth, C. M. (Ed.). (2013). Instructional-design theories and models: A new paradigm of instructional theory. New York: Routledge.

Song, J. (2020). COVID-19 pandemic and international development cooperation. Seoul: SNUCRN. derived from http://snuac.snu.ac.kr/snucrn/?p=783

Soto-Acosta, P. (2020). COVID-19 pandemic: shifting digital transformation to a high-speed gear. Information Systems Management, 37(4), 260-266

Taylor, J. (2001). The future of learning-learning for the future: Shaping the transition. Proceedings of the 20th ICDE World Congress. derived from http://www.fernuni-hagen.de/ICDE/D-2001/final/keynote_speeches/ wednesday/taylor_keynote.pdf

UNCTAD (2020a). Impact of the COVID-19 pandemic on trade and development: Transitioning to a new normal. New York: United Nations. derived from https://unctad.org/webflyer/impact-covid-19-pandemic-trade-and-developmenttransitioning-new-normal

UNCTAD (2020b). UN calls for \$2.5 trillion coronavirus package for developing countries. New York: United Nations. derived from https://unctad.org/en/pages/newsdetails.aspx?OriginalVersionID=2315

Van de Poel, J. (2020). Covid-19 and official development assistance: Current issues and challenges (Breifing paper). Belgium: Eurodad. derived from https://d3n8a8pro7vhmx.cloudfront.net/eurodad/pages/703/attachments/original/ 1592218061/Covid-19_and_ODA_briefing_final.pdf?1592218061

Woo, H., Kim, W., Yi, Y. \& Yoon, G. (2018). Examining training performance of TVET trainers with/without TVET certificate in the Republic of Korea. Journal of Technical Education and Training, 10(2), 1-12.

Yin, R. K. (2009). Case study research: Design and methods (4th ed.). CA: Sage Publications. 